\title{
Is It the Sex, the Romance, or the Living Together? The Differential Impact of Past Sexual, Romantic, and Cohabitation Histories on Current Relationship Functioning
}

\author{
Dean M. Busby \\ Brigham Young University - Provo, dean_busby@byu.edu \\ Brian J. Willoughby \\ Brigham Young University - Provo \\ Melissa L. McDonald \\ Brigham Young University - Provo
}

Follow this and additional works at: https://scholarsarchive.byu.edu/facpub

Part of the Other Social and Behavioral Sciences Commons

\section{Original Publication Citation}

Busby, D. M., Willoughby, B. J., \& McDonald, M. L. (2019). Is it the sex, the romance, or the living together? The differential impact of past sexual, romantic, and cohabitation histories on current relationship functioning. Couple and Family Psychology: Research and Practice, 8, 90-104.

\section{BYU ScholarsArchive Citation}

Busby, Dean M.; Willoughby, Brian J.; and McDonald, Melissa L., "Is It the Sex, the Romance, or the Living Together? The Differential Impact of Past Sexual, Romantic, and Cohabitation Histories on Current Relationship Functioning" (2019). Faculty Publications. 4637.

https://scholarsarchive.byu.edu/facpub/4637

This Peer-Reviewed Article is brought to you for free and open access by BYU ScholarsArchive. It has been accepted for inclusion in Faculty Publications by an authorized administrator of BYU ScholarsArchive. For more information, please contact ellen_amatangelo@byu.edu. 


\title{
Is It the Sex, the Romance, or the Living Together? The Differential Impact of Past Sexual, Romantic, and Cohabitation Histories on Current Relationship Functioning
}

\author{
Dean M. Busby, Brian J. Willoughby, and Melissa L. McDonald \\ Brigham Young University
}

\begin{abstract}
Before their current relationship, individuals may have had a variety of previous relationships such as romantic relationships, sexual relationships, and cohabiting relationships. In this study we explored the common or shared influence of these 3 types of previous relationships, and the unique influence of each type, on current relationship functioning. With a sample of more than 4,000 individuals we found that there was a significantly negative shared influence for previous romantic, sexual, and cohabiting relationships on current relationship attitudes, sexual satisfaction, commitment, and stability. Above and beyond the shared influence, there was also a unique negative influence for previous sexual and cohabiting relationships on current relationship stability. The effects were largely similar for women and for men. It appears that on average the positive lessons that are learned from previous relationship experiences are likely being overwhelmed by the negative carryover, especially in regard to relationship attitudes and relationship stability.
\end{abstract}

Keywords: sexuality, romance, cohabitation

The romantic and sexual histories of individuals are becoming more complex and varied as the pathways to an eventual marriage for those who have this goal have diversified, and some individuals are electing to never marry (Cherlin, 2009). Individuals often have romantic relationships that are not sexual, and sexual relationships that are not romantic, and some that are both. One type of relationship that usually includes both sex and romance is a cohabiting relationship. While romantic, sexual, and cohabiting relationships may share common attributes, there may also be unique influences of each of these three relational experiences. Of most importance for this study is that the asso-

Dean M. Busby, Brian J. Willoughby, and Melissa L. McDonald, School of Family Life, Brigham Young University.

Correspondence concerning this article should be addressed to Dean M. Busby, School of Family Life, Brigham Young University, 2086 JFSB, Provo, UT 84602. E-mail: dean_busby@byu.edu ciations of these three types of relationships have never been examined simultaneously so that both the shared and unique elements of these relationship types can be explored. This is the purpose of this study.

The potential differential associations of these relationship histories are important to understand because youth and adults are unsure regarding the place and timing of romance, sex, and cohabitation in relationship development. For example, a recent report from Harvard University indicates that most young adults feel very uninformed about how to understand and sequence love, sex, and friendship as they strive for a lasting romantic relationship. This lack of information leaves them vulnerable to misogyny, sexual harassment, and other types of negative relationship experiences (Weissbourd, Anderson, Cashin, \& McIntyre, 2017). Additionally, individuals' relationship histories may leave them with attitudes, opinions, and feelings about relationships that may or may not help them sustain their current relationships (Willoughby \& James, 2017). Careful research 
that helps differentiate the influence of different types of relationships could be crucial for helping young adults make wiser choices.

\section{Romantic Relationships}

In this study, we define a romantic relationship as an exclusive relationship where individuals share feelings and expressions of love and affection. Meier and Allen's (2009) relationship progression theory suggests a developmental sequence for emerging relationship skills. Historically, individuals developed from shortterm, superficial relationships, to multiple relationships, then often to a few single steady relationships. However, there has been a shift during the last several decades where there is greater diversity in romantic relationships such as individuals having no romantic experience, having sporadic involvement with different partners that often leads to cohabitation, or having frequent involvement where these relationships are short-term with multiple partners (Rauer, Pettit, Lansford, Bates, \& Dodge, 2013). Scholars have also noted that many longterm romantic relationships will now include periods of break-up and renewal, a concept coined on/off again relationships or relationship churning (Dailey, Jin, Pfiester, \& Beck, 2011; Dailey, Pfiester, Jin, Beck, \& Clark, 2009; Halpern-Meekin, Manning, Giordano, \& Longmore, 2013). Dailey and colleagues (2009) have noted that the majority of young adult relationships may now include such cycling in and out of the relationship at least once. HalpernMeeking et al. (2013) have specifically emphasized the importance of conducting research such as this study where we explore whether this "relationship churning" influences the stability of subsequent marriage or other relationships.

This historical shift parallels the emerging adulthood literature - a proposed life stage lasting from the late teens through the mid- to late-20s (Arnett, 2000). This proposed developmental stage has been presented as a time of instability, exploration, and self-focus. Many of these emerging adults are not focused on having a lasting romantic partner. Indeed, one emerging adult scholar noted that, "observation of the lives of the majority of young people shows that they may move between transitory and inconsistent states with regard to relationships"
(Shulman \& Connolly, 2013, p. 29). As a result, it is expected that emerging adults will have multiple romantic partners. However, the literature exploring the influence of these multiple relationships is sparse. There is some literature on adolescent relationship development and influence, but recognizably, for young adults, there is likely a different process. The experiences of emerging adults are dramatically different than those of preceding generations as "hanging-out" and "hooking-up" has replaced some of the traditional experiences of dating for many young adults (Siebenbruner, 2013). In fact, when evaluating emerging adults, it would not be uncommon to discover that the term "dating" is almost omitted from their conversations. Some scholars found that one third of the female seniors in college had been asked on two or less dates and only $50 \%$ had been asked on six or more dates during their three plus years in college (Woodger, Holman, \& Young, 2007).

The infrequency of dating, in favor of casual romantic experiences, such as hanging-out, may be beneficial or detrimental for long-term relationship success. Seiffge-Krenke (2003) suggested that greater involvement in romantic relationships early on leads to later positive romantic outcomes. However, we know that the number of previous partners does have an influence on current levels of functioning (Green, Campbell, \& Davis, 2007; Herzog \& HillChapman, 2013; Leck, 2006; Saribay \& Andersen, 2007). These and other authors have demonstrated that previous relationship break ups or difficulties can lead to more problems in future relationships. Moreover, past relationships can have a negative effect on future relationships (Brimhall, Wampler, \& Kimball, 2008). We also know that the process of forming new relationships and breaking up with multiple partners over time can be problematic. This can lead to a decrease in an individuals' commitment to future relationships and associations with increased levels of delinquency (Cui, Ueno, Fincham, Donnellan, \& Wickrama, 2012; Davies \& Windle, 2000; Simpson, 1987; Teachman, 2003). It is possible that extensive relational experiences that do not always work out well may contribute to individuals being more cautious and slower to commit in subsequent relationships. It is also possible that some individuals struggle to fully recover from the emotional process of ending a long-term relation- 
ship, thereby carrying negative emotions into their new relationships.

From the work previously reviewed the obvious question arises as to whether is it better for individuals to have many romantic relationships to gain experience and greater understanding or is it more ideal to have fewer romantic relationships to reduce the negative effects from terminated relationships? In this study we hope to at least partially address this question.

\section{Sexual Relationships}

Sometimes sexual relationships are embedded in romantic relationships and sometimes they are not. Social interaction often leads to individuals hooking up by participating in some degree of casual sexual activity - ranging from kissing to intercourse. Glenn and Marquardt (2001) suggested women in their college sample reported $91 \%$ of these hookups happened "very often" or "fairly often." Consequently, approximately $90-95 \%$ of married individuals have had premarital intercourse (Halpern \& Kaestle, 2013; Teachman, 2009). Furthermore, unlike some romantic relationships, hooking-up carries no promise of long-term commitment. This suggests that some people in today's culture are centered on low-commitment relationships. These types of relationships are typically created solely for the physical pleasure and may even evolve into an ongoing, yet noncommitted relationship (i.e., "friends-with-benefits"; Banker, Kaestle, \& Allen, 2010).

Similar to romantic relationships, these previous casual sexual relationships also influence current relationship functioning. Specifically, sexual involvement and the timing of sexual involvement influences future relationship functioning. In particular, the research demonstrates that early sexual involvement in a relationship and sexual involvement with different partners across time negatively influences the development of relationship communication patterns, sexual quality, and stability in couples (Busby, Carroll, \& Willoughby, 2010; Busby, Willoughby, \& Carroll, 2013; Sassler, Addo, \& Lichter, 2012; Teachman, 2003). Specifically, Teachman (2009) found that among women, having premarital intercourse with more partners than just their future spouse indicated an increase in the risk of subsequent marital disruption. Moreover, multiple sexual partners may "weaken the marital bond by heightening awareness of alternatives to one's marital partner as sources of sexual intimacy and fulfillment" (p. 198).

In a culture where sexual relationships are common, similar questions to those previously mentioned are raised. Is it better for individuals to have many sexual relationships so they are able to gain experience and improve their ability to develop sexual efficacy? In contrast, is it more ideal to have fewer sexual relationships?

\section{Cohabiting Relationships}

While it is beyond the scope of this article to describe the extensive literature on cohabiting couples, it is important to note that most marriage relationships are now preceded by cohabitation (Kennedy \& Bumpass, 2008). In addition, cohabitation has been consistently linked to negative relationship outcomes, especially when the cohabitation is not with an eventual marriage partner (Jose, O'Leary, \& Moyer, 2010). While selection factors likely account for some of these associations, scholars have noted that cohabiters continue to report less positive outcomes, even when accounting for potential selection effects (Dush, Cohan, \& Amato, 2003). These explanations often center around reports of less marital commitment among premarital cohabiters (Kuperberg, 2014; Willoughby, Carroll, \& Busby, 2012). While recent work has suggested that these findings may be diminishing in recent cohorts (Kuperberg, 2014; Manning \& Cohen, 2012), a large body of existing literature continues to suggest that premarital cohabitation may carry some risks for long-term relationship success. However, because virtually all cohabiting relationships are also sexual and romantic in nature it is difficult to determine whether the possible negative effects might be from these relationship processes rather than anything unique that is part of the cohabiting experience. This study should help with beginning to unravel the potentially unique influence of cohabitation above and beyond romance and sex.

\section{Theoretical Model}

Scholars have attempted to organize their thinking about the influence of past relationship history, regardless of the type, by developing 
different theoretical models (Meier \& Allen, 2009). Some of these models have emphasized behavioral systems that are developed such as affiliation, sexuality, attachment, and caregiving (Furman \& Wehner, 1994), while others have emphasized the phases relationships go through such as initiation, affiliation, intimacy, and commitment (Connolly \& Goldberg, 1999). While it is not possible to fully test phase models without longitudinal data, we attempt to combine common elements from these two types of theories into the model presented in Figure 1. On the far left of the model are the central exogenous variables of interest that have not been tested simultaneously before for common and unique effects. The multiple arrows leading out of the unique effects of these three relationship types indicate that we will explore whether, beyond the common effects included in the latent variable, each relationship type might influence all the other variables to the left in the model. This approach to using both the shared and the unique elements of a variable in a structural model has been used by several researchers in the past but not with relationship types as we do in this study (Galovan, Holmes, \& Proulx, 2017; Ledermann \& Kenny, 2012).

To isolate the influence of sexual, romantic, and cohabitation relationship histories as com- pared with other variables that influence relationship outcomes, we used a number of control variables that are commonly used in this type of research including relationship length, education, and religiosity (Tolman \& Diamond, 2013; Willoughby et al., 2012). Age would have been another natural control variable but it was highly correlated with relationship length so we selected relationship length instead.

The constructs in the middle of the model including sexual satisfaction and effective communication capture the primary elements of the behavioral system and phase models that emphasize both the sexual and emotional intimacy that develop through effective communication and sexuality. The constructs to the far right of the model represent the relationship bonding variables that develop as the result of emotional and sexual intimacy such as commitment, relationship satisfaction, and stability. To the previous theories, we add the crucial variable of relationship attitudes (Jensen, Willoughby, Holman, Busby, \& Shafer, 2015) that is a newer variable we expected might be a common outcome of multiple relationship experiences as described by Teachman (2009) and others (see Willoughby \& Carroll, 2016). In Teachman's work he contemplates whether the negative effects of cohabitation and multiple sexual part-

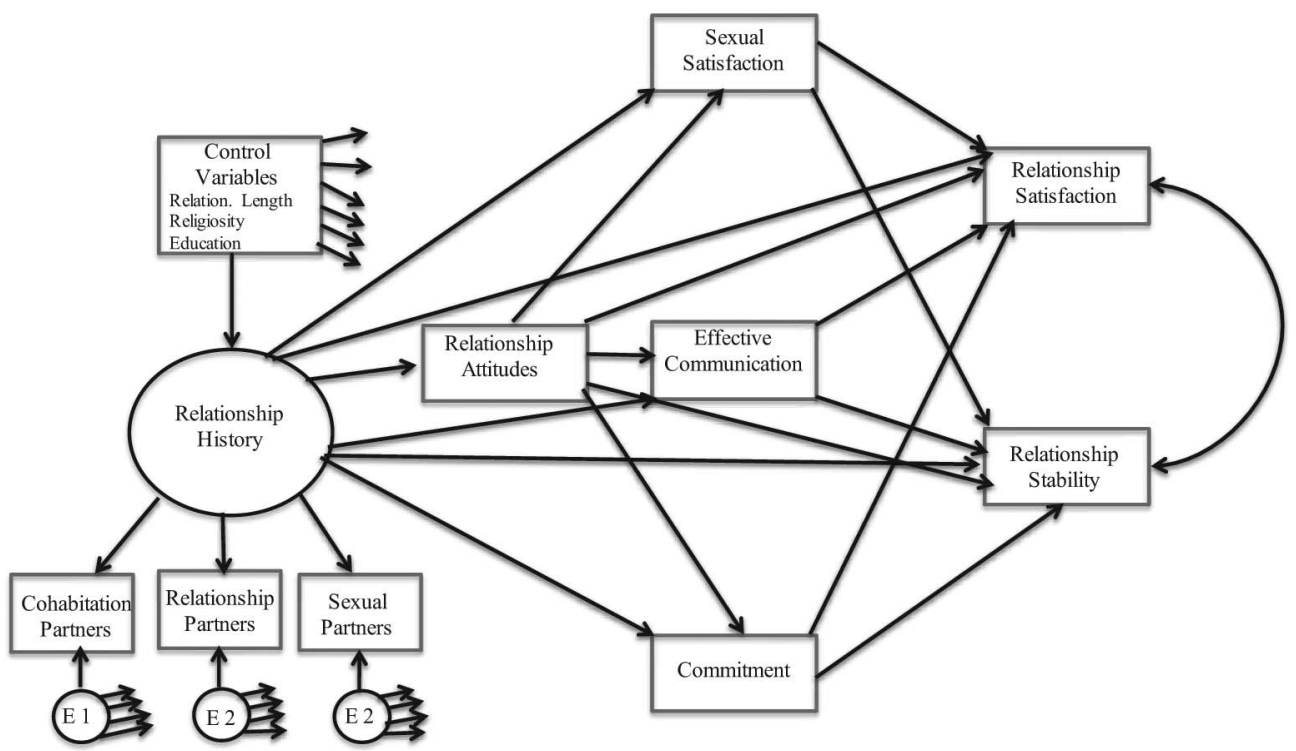

Figure 1. Initial model testing the influence of sexual, relationship, and cohabiting histories. 
ners might be because of individuals learning that relationships are fragile and painful rather than enduring and satisfying. While this construct is associated with attachment, correlations with attachment measures from previous studies indicate it is only moderately correlated with attachment measures (Jensen et al., 2015). These findings suggest the measure is capturing overall attitudes about relationships rather than attachment behaviors and internal working models. Consequently, relationship attitudes is a scale that evaluates whether individuals view relationships as positive or rewarding as compared with negative, challenging, and punishing.

Through the evaluation of this model we attempt to fill important gaps in the literature by comprehensively exploring the common and unique influence of the three primary types of relationships that individuals experience. While some studies have explored the influence of one type of relationship on a few variables, none of the studies have attempted to explore all three types of relationships in a comprehensive model that includes the new variable of relationship attitudes as suggested by recent research.

\section{Purpose of This Study}

The purpose of our study is to explore how different relationship histories influence current relationship functioning. Some individuals have many romantic relationships and few sexual relationships. Others have few romantic relationships and many sexual relationships. There are also those who have few or no cohabiting relationships and some have many cohabiting relationships. Because many relationships combine elements of romance, sex, and cohabitation, we expect that there will be a common or shared influence of previous relationship experiences that is captured by a latent variable called relationship history. We expect this relationship history to be associated with current relationship functioning. Conversely, no matter how much shared variance exists between romance, sex, and cohabitation, there is still likely some unique influence of romantic, sexual, or cohabiting relationships on current relationship functioning that is not captured by the latent variable. Therefore, our first two research questions were the following:
1. Is there a common or shared influence from past sexual, romantic, and cohabiting relationships on current relationship functioning?

2. Is there a unique influence of each of these three types of relationships on current relationship functioning?

In addition, the effects of previous relationships may be different for women and men so our third research question is:

3. Does the combined or unique influence of previous relationship types change based on gender?

We sought to answer these questions by evaluating the model in Figure 1. This model allows us to explore the common effects, or relationship history, that are shared by all relationship types as compared with the unique influence of cohabitation, sexuality, and romance.

\section{Method}

\section{Participants}

The participants for this study were selected from a recently collected national dataset from the RELATionship Evaluation Questionnaire (RELATE; Busby, Holman, \& Taniguchi, 2001). Our sample consisted of 4,264 individuals, drawn from a larger dataset by selecting only those in a serious relationship who indicated they were either exclusively dating their partner, engaged, or married. Thirty-two percent of the participants were in an exclusive dating relationship, $44 \%$ were engaged, and $24 \%$ were married. Sixteen percent of the participants had previously been divorced. The gender distribution was $37 \%$ male and $63 \%$ female. The participants ranged in age from 18 to 79 , with the mean age of the sample being 31.1 years $(S D=9.58)$. The ethnic distribution was $72 \%$ percent Caucasian, 9\% African American, 5\% Latin American, 4\% Asian American, $4 \%$ mixed ethnicities, and $6 \%$ answered "other." These individuals reported a variety of religious affiliations; 32\% Protestant, 19\% Catholic, 24\% nonaffiliated, 5\% Latter-day Saint (Mormon), 3\% Jewish, 2\% Buddhist, and 15\% listed "other." 


\section{Procedure}

These individuals completed RELATE online after being exposed to the instrument through a variety of settings (as part of a class, given by a relationship educator or therapist, searching for it on the web). Participants take RELATE because they or their instructor or therapist are interested in getting the assessment report that details the strengths and weaknesses in their relationship. Nobody is excluded from taking RELATE except for those under the age of 18 because of the sensitive nature of some of the questions about violence in the family of origin and sexuality in the current relationship. Each participant was asked to complete the $300+$ item survey independently. Participants typically take between 30 to 60 min to complete the survey. All of the participants completed an appropriate consent form before the completion of the RELATE instrument and the study was approved by the Institutional Review Board (IRB) committee at the authors' university.

\section{Measures}

For this study, all of the measures came from the RELATE instrument. We examined the constructs of relationship satisfaction, sexual satisfaction, effective communication, commitment, relationship stability, relationship attitudes, number of sexual partners, number of romantic relationships, and number of cohabitation partners.

Romantic relationships. The number of romantic relationships was measured by asking the question, "How many serious romantic relationships have you had with different people (including your current partner if appropriate)?" The average number of romantic relationships was $2.90(S D=1.7)$. Participants that reported more than 15 romantic relationships were removed as outliers $(N=10)$. We were unable to find a comparison sample in the literature for the variable assessing the number of romantic partners so it is not clear whether the current sample was higher or lower than national norms on this variable.

Sexual partners. The number of sexual partners was measured by asking the question, "With how many people have you had sexual intercourse (including your current partner if appropriate)?" The average number of sexual partners was $7.53(S D=9.5)$. In the current study participants who reported more than 100 sexual partners were removed as outliers $(N=$ 9 ). Several studies have reported mean number of sexual partners in a similar age range to the current sample including means of 7.05 from Liu et al. (2015) and means of 6.31(Stanley et al., 2018). The mean for the Stanley et al. study was likely lower than average for lifetime sexual partners because the mean age of the sample was approximately 26, and the question asked about the number or previous sexual partners so participants were not counting their current partner.

Cohabitation partners. The number of cohabiting partnerships was measured by asking the question, "In your lifetime, with how many romantic partners have you cohabited prior to marriage (including your current partner if applicable)?" The average number of cohabiting partners was $0.88(S D=1.07)$. This number is similar to the average number of cohabiting partners, .80, calculated from scholars using governmental statistics on cohabitation and marriage (Goodwin, Mosher, \& Chandra, 2010), though this number is likely low as the maximum value participants could report for cohabiting unions was " 3 or more." In the current study participants who reported more than 10 cohabiting relationships were removed as outliers $(N=4)$.

Sexual satisfaction. This scale was measured with six items from Rust and Golombok's (1986) Golombok Rust Inventory of Sexual Satisfaction to assess how satisfied participants were with their sexual relationship (e.g., frequency of intercourse, amount of variety, time spent on foreplay, etc.). This inventory has shown adequate reliability and predictive validity in a variety of studies over the years (Brown et al., 2017; Leonhardt, Willoughby, Busby, Yorgason, \& Holmes, 2018). Items were rated on a 5-point Likert-type scale ranging from $1=$ never to $5=$ very often. Internal consistency of the sexual satisfaction construct was high (Cronbach's $\alpha=.84$ ). The average report of sexual satisfaction was $3.67(S D=.85)$.

Relationship satisfaction. To assess the level of relationship satisfaction, we used seven items evaluating the participant's degree of satisfaction in their relationship (e.g., satisfaction with how conflicts were resolved, the love experienced, the overall relationship, etc.). Each 
item was answered on a 5-point Likert scale $(1=$ very dissatisfied to $5=$ very satisfied $)$. The Cronbach's $\alpha$ for the relationship satisfaction scale was .90 . The average score was 3.78 $(S D=.86)$. Additional test-retest reliability estimates in past research were between .76 and .78 (Busby et al., 2001). Validity data have also shown the strength of this scale in both correlational and longitudinal research as an outcome of other relational processes (Halford et al., 2017; Kim Halford et al., 2015). In previous research this scale was also highly correlated with other relationship quality and satisfaction measures in cross-sectional and longitudinal research (Busby et al., 2001; Busby, Ivey, Harris, \& Ates, 2007).

Commitment. Commitment was assessed with four items from Stanley and Markman's Commitment Inventory (Stanley \& Markman, 1992) that asked participants to select the degree to which they agreed with each of the statements (e.g., "My relationship with my partner is more important to me than almost anything else in my life."). Items were on a 5-point Likert scale ranging from 1 = strongly disagree to $5=$ strongly agree. Cronbach's $\alpha$ for the commitment scale was .77. The average report of commitment was $4.38(S D=.66)$. Validity information on this scale from previous research showed that it has been effective as either a predictor of other relationship variables or as an outcome (Stanley, Amato, Johnson, \& Markman, 2006; Stanley, Markman, \& Whitton, 2002).

Communication. The communication scale consisted of 15 items used to measure how often participants were able to communicate love and appreciation, were able to engage in empathic communication, were able to communicate clearly, and were able to communicate in a soothing fashion during times of conflict. The response scale was a 5-point Likert-type scale ranging from $1=$ never to $5=$ very often. Internal consistency of the communication scale was high $(\alpha=.91)$. The average report of communication was $3.93(S D=.50)$. In terms of test-retest and validity information on this scale, the communication items have been shown to have test-retest values between .70 and .83 and were appropriately correlated with a version of a commonly used Relationship Quality measure as predicted (Busby et al., 2001). These scales have also been shown in both correlational and longitudinal research to be predictive of couple outcomes and are sensitive to change in couple intervention studies (Bradford Witting \& Busby, 2018; Busby et al., 2007).

Relationship stability. The relationship stability scale consisted of three items assessing how stable their relationship was (e.g., how often they have broken up or separated, thought that their relationship was in trouble, and talked about ending the relationship with their partner). These items were adapted from earlier work by Booth, Johnson, and Edwards (1983). The response scale was a 5-point Likert style scale, ranging from $1=$ never to $5=$ very often . The average stability score was $4.06(S D=$ $.83)$. The Cronbach's $\alpha$ was .81. Previous studies have shown this scale to have test-retest reliability values between .78 and .86 , and the scale was appropriately correlated with other relationship quality measures. Consequently the scale has been shown to be valid for use in cross-sectional and longitudinal research (Busby, Holman, \& Niehuis, 2009; Busby et al., 2001, 2007).

Relationship attitudes. The relationship attitudes scale assessed the participants' attitudes toward romantic relationships (e.g., thinking relationships are safe, secure, rewarding; or confusing, unfair, anxiety-provoking) based on what they have experienced in previous romantic relationships. This scale is an adaptation of a commonly used scale used to evaluate the impact of the family of origin relationships on current relationship attitudes (Holman \& Busby, 2011; Yoshida \& Busby, 2012). Items were changed to reference previous romantic relationships rather than family of origin relationships. Items were rated on a 5-point Likert scale ranging from $1=$ strongly disagree to $5=$ strongly agree. The Cronbach's $\alpha$ was .77 with the average report being $3.65(S D=.83)$.

Control variables. We controlled for religiosity, education, and relationship length. Religiosity was measured through four items that asked the participants to select the degree to which the item described them (e.g., "Spirituality is an important part of my life"). Items were rated on a 5-point Likert-type scale ranging from $1=$ never to $5=$ very often. Factors included how frequently they prayed, attended a religious service, and considered spirituality an important part of their lives. Internal consis- 
tency of the religiosity construct was high $(\alpha=$ .89). The average report of religiosity was 2.89 $(S D=1.29)$.

The remaining control variables were single item demographic variables with one exception. Relationship length for married couples included both the amount of time they dated before marriage and the length of their marriage, if applicable.

\section{Results}

Table 1 includes the bivariate correlations between the variables in Model 1 for men and women. The correlations illustrate several important patterns in the data. First, the moderate correlations, around .35 , between the number of romantic, sexual, and cohabiting partners provides evidence that using a common fate model is appropriate as there is sufficient correlations to produce reliable indicators of a latent variable (Ledermann \& Kenny, 2012). Second, the number of sexual partners, as compared with the number of romantic or cohabiting partners, had the strongest relationship with the other variables in the study such as relationship attitudes, relationship stability, and satisfaction. Third, the differences between women and men were small.

The next step in the analysis was to evaluate the model in Figure 1. Although not diagrammed, each of the unique elements, or error terms, for the three variables contributing to the latent relationship history variable were regressed on all the endogenous variables. Only two paths were significant and were retained in the results listed in Figure 2. All of the coefficients listed in Figure 2 were significant at $p<$ .05. Also the control variables were regressed on all of the other variables in the model but are not drawn as were the covariances between the endogenous variables. As expected from the correlation matrix, the influence of education was typically weak or nonsignificant on most of the variables in the model, while the influence of religiosity was moderate on the number of cohabiting and sexual partners and communication and commitment. The influence of relationship length was moderate on relationship satisfaction, sexual satisfaction, and communication.

The model was evaluated for both men and women. The model fit statistics for the female and male models indicated good fit to the data.
For the female model the $\chi^{2}$ was 236.78 ( $p<$ $.000)$, the comparative fit index (CFI) was .98, the Tucker-Lewis Index (TLI) was .95, and the root mean square error of approximation (RMSEA) was .05. For the male model the $\chi^{2}$ was $127.99(p<.000)$, the CFI was .98 , the TLI was .95 , and the RMSEA was .04.

Next we evaluated these models for equivalency by constraining the values to be equal across sex. The $\chi^{2}$ difference when the measurement coefficients were constrained to be equal was $.171, p=.68$, indicating that the measurement coefficients for women and men were equivalent. The $\chi^{2}$ difference when the structural coefficients were constrained to be equal was $92.62, p<.000$, indicating that the structural coefficients for women and men were not equivalent. In Figure 2 the structural coefficients that were significantly different between genders are indicated in bold. Only two coefficients were significantly different; the pathways between relationship history and the number of sexual partners and relationship stability. The $\chi^{2}$ difference when the measurement intercepts were constrained to be equal was $10.82, p<$ .01 , indicating that the measurement intercepts for women and men were not equivalent. The $\chi^{2}$ difference when the structural intercepts were constrained to be equal was $162.68, p<.001$, indicating that the structural intercepts for women and men were not equivalent. Finally, the $\chi^{2}$ difference when the covariances of the structural errors were constrained to be equal was $235.84, p<.001$, indicating that these covariances were not equivalent for women and men.

The structural coefficients listed in Figure 2 indicate that most of the variance of the three relationship history variables flowed through the common or latent variable pathways and that all of these associations were negative. The strongest associations for this common latent factor of relationship history was with relationship attitudes and stability. There were only two significant paths directly from the unique variances of cohabiting partners and sexual partners and they were both on relationship stability. These associations showed that as the number of cohabiting and sexual partners increased relationship stability decreased. The number of romantic partners did not have any unique associations. 


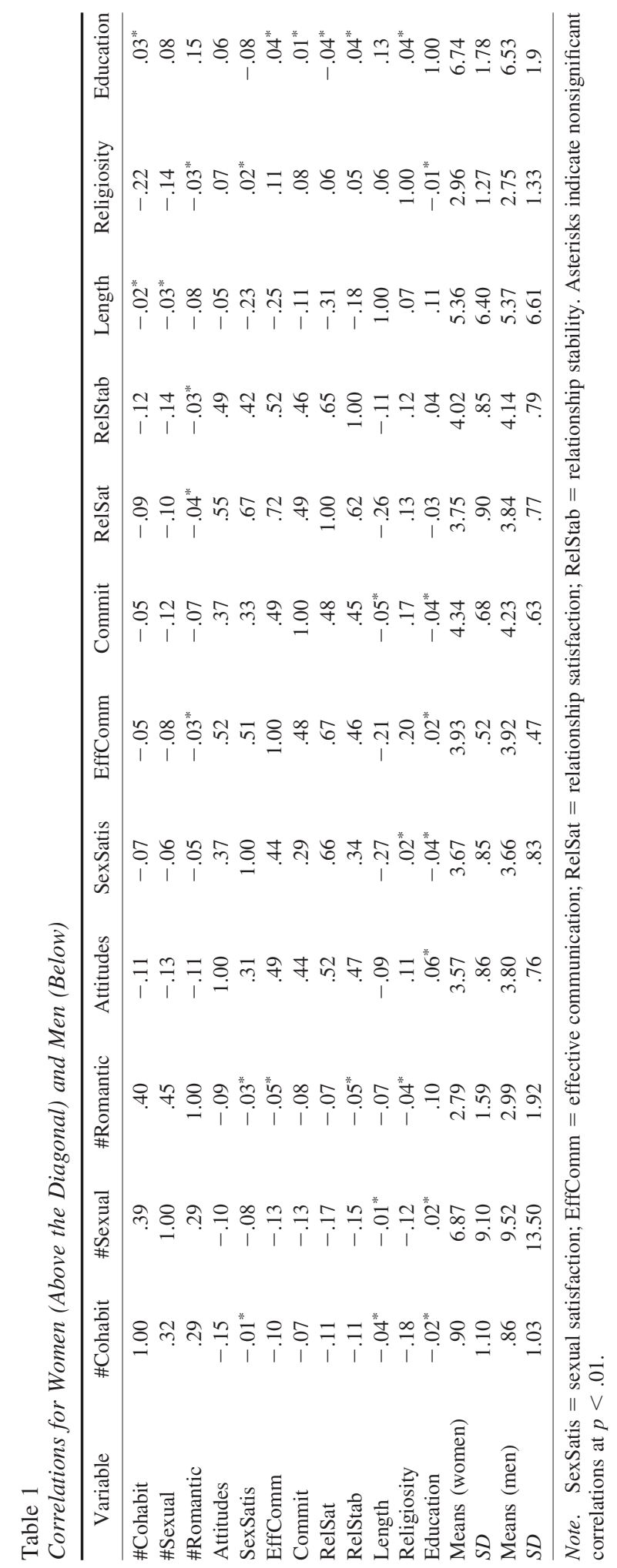




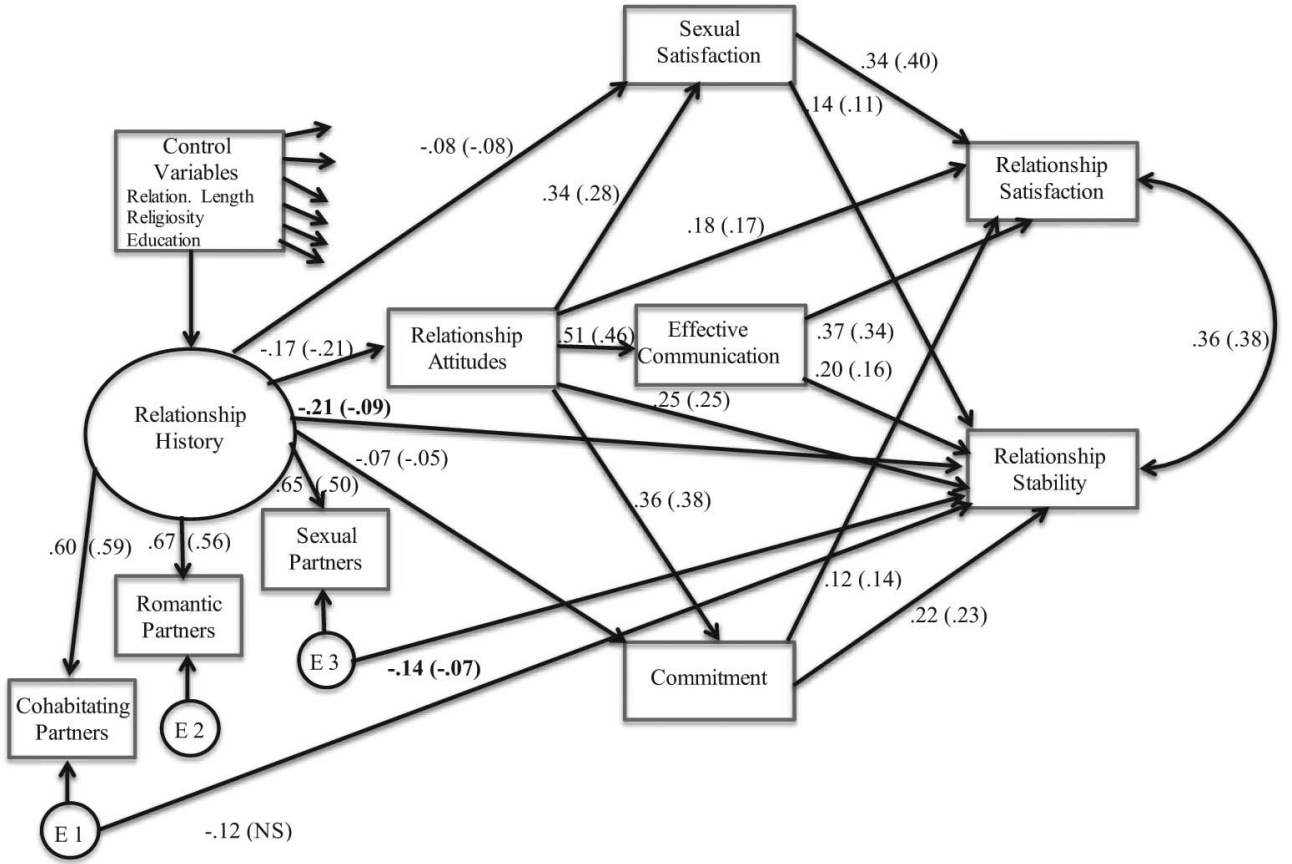

Figure 2. Final model. Coefficients listed first are for females and those listed in parentheses are for males.

\section{Discussion}

Our purpose in conducting this study was to understand whether there was a common or shared association from past romantic, sexual, and cohabiting relationships with current relationship functioning. It was also our intention to explore the unique associations of each type of relationship and whether the associations were distinct for women and men. There does appear to be shared attributes between these types of relationships that are negatively associated with current relationship functioning.

What our findings illustrate is that when the correlations between these three relationship types move together or are shared they have a significantly negative association, especially on relationship attitudes and relationship stability. Why? It is possible that this latent variable of relationship history is largely picking up on the damage that can occur because of breakups of serious relationships as mentioned earlier and backed up by research from other scholars (Cui et al., 2012; Davies \& Windle, 2000; Simpson, 1987; Teachman, 2003). While surely individ- uals learn both positive and negative things from past relationships, perhaps the positives are overwhelmed by one or more serious breakups that leave individuals with less hopeful attitudes about relationships and less stable future relationships. The relationship attitude scale is strongly associated with all of the other variables in this study from sexual satisfaction to communication and commitment, and finally to relationship satisfaction and stability.

Teachman (2003) may have been correct when he speculated that some of what is learned from previous breakups may be the transitory nature of relationships as well as how to become better at breaking up. Perhaps individuals with extensive previous relationship experience become less patient with future relationships and more sensitive to negative relational signs. This may influence them to move toward breaking up faster that would explain the negative effect on current relationship stability. It may also be that those who are better at making relationships work from the beginning are more likely to stay in relationships and, therefore, have fewer num- 
bers of relationships of all types. However, if this were the dominant pattern we should still see a significant common association for the relationship history latent variable but it would be a positive rather than a negative association. These speculations lead us to ponder how future research with these types of variables should consider unique trajectories for different types of couples as those who have few relationships of all types may be quite different than those who have many different relationships of all types. Also important, it may be very enlightening to have individuals rate the impact of each relationship they have been in to see if what is occurring is an accumulation of small effects across many relationships or less common but more traumatic effects of a single breakup.

We also found that over and above the common or shared associations of relationship history there was a unique negative association on relationship stability for both the number of cohabiting and the number of sexual relationships. These findings are consistent with previous research that shows that multiple cohabiting and sexual relationships were negatively associated with future relationship stability (Busby et al., 2013; Kennedy \& Bumpass, 2008; Sassler et al., 2012). We thought there might be unique associations on other variables such as attitudes, sexual satisfaction and commitment, but the unique associations appear to be exclusively with relationship stability. Though this association is not strong it is worth noting as the factor loadings were large enough to suggest that most of the variance is going through the common effect so what little variance is left still has a significant influence on relationship stability and the effect is stronger for women than men. The unique effect of the number of sexual partners, distinct from its association with romance or cohabitation, appears to specifically be associated with women feeling less stable in their current relationships. This is more evidence for the potential salience of a sexual restraint model versus a sexual compatibility model (Busby et al., 2013) as well as for the commitment model from Stanley and associates that suggests early sexual involvement may impede the ability to make better relationship choices (Stanley, Rhoades, \& Markman, 2006).

Still, although in the bigger picture the general trend in the results was for the associations to be stronger for women than for men, very few of these coefficients were significantly different. Consequently, the most accurate statement would be that the associations of relationship history and relationship attitudes on all the other variables in the model are largely the same for men and women. There are some differences that ought to be more carefully explored, but so far most of the variables are not significantly different for the sexes.

\section{Limitations and Future Directions}

There are several limitations to this study that should be noted when interpreting the findings. The sample is not representative so consequently the results may be skewed in unexpected directions. Also, while we asked participants to rate the influence of previous relationships on their current attitudes, a longitudinal sample where individuals are followed in and out of previous relationships would likely yield more depth and predictive power to previous relationship histories on current relationship functioning.

Additionally, there are likely unique issues experienced by LGBTQIA individuals that may influence their relationship histories and that may influence how relationship history is associated with relationship outcomes. Unfortunately, the sample did not allow us to explore these issues and we were unable to locate research by scholars who have studied how relationship histories influence relationship outcomes with these groups.

Even with the limitations, this is the first study we are aware of that allows for an investigation of the shared variance of different types of past relationship histories on current relationship functioning while also exploring the unique associations of previous romantic, cohabiting, and sexual experiences. From the results of this study it is evident that more closely studying previous relationship history, including more details about both the positive and negative carryover into current relationships, is likely to help scholars and couples better understand and improve current relationship functioning. The findings from this study suggest that the combined shared association of previous relationship history is negative and that the unique associations of previous sexual and cohabiting relationships are also negative as it is associated with lower levels of relationship sta- 
bility. Clearly more studies need to be conducted on relationship history and more effort needs to be done to help individuals developmentally mature in the relationship area without the negative spillover that can occur after breakups.

\section{Implications}

Most individuals have had previous relationships with a variety of partners. In fact on average individuals in this study had experienced three romantic relationships, eight sexual relationships, and one cohabiting relationship. As has been noted by other scholars on adult romantic relationships, the alternatives to marriage are as diverse and available as they have been at any time in modern history (Cherlin, 2009; Finkel, Hui, Carswell, \& Larson, 2014). Currently, the vast majority of couples are electing to cohabit before marriage and higher percentages of individuals are staying single longer than ever before. Nevertheless, this does not change the fact that close to $90 \%$ of people will eventually marry and that almost all report that they want to marry. (Finkel et al., 2014). These realities make it even more important that we consider the unique effect of different types of past relationship choices on current relationship functioning as we have attempted to do in this study.

At the least the present study implies that applied professionals should ask about relationship attitudes and histories as potential points of education or intervention. As these relationship histories become more complex and numerous they are likely to be associated with a variety of attitudes which are also likely to be related to relationship outcomes. The findings from this study also imply that applied professionals may be able to enhance current relationships. This may be done by developing strategies, programs, or modules that help individuals and couples identify enduring negative expectations they have about relationships. Once these negative expectations are identified applied professionals can help them challenge these expectations, adopt more hopeful and forward thinking perspectives, and behaviorally translate these positive expectations into their current relationships. Another important implication is to begin to help youth contemplate the potential spillover that might occur from all relationship types into future relationships that they may want to be more enduring. The results from this study do not suggest that any one type of relationship is ideal; rather they suggest that as the number of relationships accumulate across time there is an association with negative relationship attitudes and outcomes. Consequently, it would be useful to help youth and young adults understand that matters of the heart are serious and even casual sexual relationships have consequences. It might help to consistently teach the markers of positive friendship and the mechanism for building strong relationships so that fewer but better relationships are enjoyed. Finally, there are likely many exceptions to the overall patterns in this study in that some individuals likely learn needed lessons and perspectives from previous relationships and appropriately learn to carry forward these lessons for improved future relationships. Studying these exceptions would be important for informing both basic research and applied programs.

\section{References}

Arnett, J. J. (2000). Emerging adulthood. A theory of development from the late teens through the twenties. American Psychologist, 55, 469-480. http:// dx.doi.org/10.1037/0003-066X.55.5.469

Banker, J. E., Kaestle, C. E., \& Allen, K. R. (2010). Dating is hard work: A narrative approach to understanding sexual and romantic relationships in young adulthood. Contemporary Family Therapy, 32, 173-191. http://dx.doi.org/10.1007/s10591009-9111-9

Booth, A., Johnson, D. R., \& Edwards, J. N. (1983). Measuring marital instability. Journal of Marriage and the Family, 45, 387-394. http://dx.doi.org/10 $.2307 / 351516$

Bradford Witting, A., \& Busby, D. M. (2018). The long arm of trauma during childhood: Associations with resources in couple relationships. Journal of Marital and Family Therapy. [Advance online publication.] http://dx.doi.org/10.1111/jmft.12354

Brimhall, A., Wampler, K., \& Kimball, T. (2008). Learning from the past, altering the future: A tentative theory of the effect of past relationships on couples who remarry. Family Process, 47, 373387. http://dx.doi.org/10.1111/j.1545-5300.2008 .00259.x

Brown, C., Carroll, J. S., Yorgason, J. B., Busby, D. M., Willoughby, B. J., \& Larson, J. H. (2017). A common-fate analysis of pornography acceptance, use, and sexual satisfaction among heterosexual married couples. Archives of Sexual Behav- 
ior, 46, 575-584. http://dx.doi.org/10.1007/ s10508-016-0732-4

Busby, D. M., Carroll, J. S., \& Willoughby, B. J. (2010). Compatibility or restraint? The effects of sexual timing on marriage relationships. Journal of Family Psychology, 24, 766-774. http://dx.doi .org/10.1037/a0021690

Busby, D. M., Holman, T. B., \& Niehuis, S. (2009). The association between partner- and self-enhancement and relationship quality outcomes. Journal of Marriage and Family, 71, 449-464. http://dx.doi.org/10 .1111/j.1741-3737.2009.00612.x

Busby, D. M., Holman, T. B., \& Taniguchi, N. (2001). RELATE: Relationship evaluation of the individual, family, cultural, and couple contexts. Family Relations, 50, 308-316. http://dx.doi.org/ 10.1111/j.1741-3729.2001.00308.x

Busby, D. M., Ivey, D. C., Harris, S. M., \& Ates, C. (2007). Self-directed, therapist-directed, and assessment-based interventions for premarital couples. Family Relations, 56, 279-290. http://dx.doi .org/10.1111/j.1741-3729.2007.00459.x

Busby, D. M., Willoughby, B. J., \& Carroll, J. S. (2013). Sowing wild oats: Valuable experience or a field full of weeds. Personal Relationships, 20, 706-718. http://dx.doi.org/10.1111/pere.12009

Cherlin, A. J. (2009). The marriage-go-round: The state of marriage and the family in America today. New York, NY: Knopf.

Connolly, J., \& Goldberg, A. (1999). Romantic relationships in adolescence: The role of friends and peers in their emergence and development. In W. Furman, B. B. Brown, \& C. Feiring (Eds.), The development of romantic relationships in adolescence (pp. 266-290). New York, NY: Cambridge University Press. http://dx.doi.org/10.1017/ CBO9781316182185.012

Cui, M., Ueno, K., Fincham, F. D., Donnellan, M. B., \& Wickrama, K. A. (2012). The association between romantic relationships and delinquency in adolescence and young adulthood. Personal Relationships, 19, 354-366. http://dx.doi.org/10.1111/j .1475-6811.2011.01366.x

Dailey, R. M., Jin, B., Pfiester, A., \& Beck, G. (2011). On-again/off-again dating relationships: What keeps partners coming back? The Journal of Social Psychology, 151, 417-440. http://dx.doi .org/10.1080/00224545.2010.503249

Dailey, R. M., Pfiester, A., Jin, B., Beck, G., \& Clark, G. (2009). On-again/off-again dating relationships: How are they different from other dating relationships? Personal Relationships, 16, 23-47. http:// dx.doi.org/10.1111/j.1475-6811.2009.01208.x

Davies, P. T., \& Windle, M. (2000). Middle adolescents' dating pathways and psychosocial adjustment. Merrill-Palmer Quarterly, 46, 90-118.

Dush, C. M. K., Cohan, C. L., \& Amato, P. R. (2003). The relationship between cohabitation and marital quality and stability: Change across cohorts? Journal of Marriage and Family, 65, 539-549. http:// dx.doi.org/10.1111/j.1741-3737.2003.00539.x

Finkel, E. J., Hui, C. M., Carswell, K. L., \& Larson, G. M. (2014). The suffocation of marriage: Climbing mount Maslow without enough oxygen. Psychological Inquiry, 25, 1-41. http://dx.doi.org/10 .1080/1047840X.2014.863723

Furman, W., \& Wehner, E. (1994). Romantic views: Toward a theory of adolescent romantic relationships. In R. Montemajor, G. R. Adams, \& T. P. Gullotta (Eds.), Personal relationships during adolescence (pp. 168-195). Thousand Oaks, CA: Sage.

Galovan, A. M., Holmes, E. K., \& Proulx, C. M. (2017). Theoretical and methodological issues in relationship research: Considering the common fate model. Journal of Social and Personal Relationships, 34, 44-68. http://dx.doi.org/10.1177/ 0265407515621179

Glenn, N., \& Marquardt, E. (2001). Hooking up, hanging out, and hoping for Mr. Right: College women on dating and mating today. New York, NY: Institute for American Values.

Goodwin, P. Y., Mosher, W. D., Chandra, A., \& the National Center for Health Statistics. (2010). Marriage and cohabitation in the United States: A statistical portrait based on cycle 6 (2002) of the National Survey of Family Growth. Vital Health Statistics, 23, 1-45.

Green, J. D., Campbell, W. K., \& Davis, J. L. (2007). Ghosts from the past: An examination of romantic relationships and self-discrepancy. The Journal of Social Psychology, 147, 243-264. http://dx.doi .org/10.3200/SOCP.147.3.243-264

Halford, W. K., Rahimullah, R. H., Wilson, K. L., Occhipinti, S., Busby, D. M., \& Larson, J. (2017). Four year effects of couple relationship education on low and high satisfaction couples: A randomized clinical trial. Journal of Consulting and Clinical Psychology, 85, 495-507. http://dx.doi.org/10 $.1037 / \mathrm{ccp} 0000181$

Halpern, C. T., \& Kaestle, C. E. (2013). Sexuality in emerging adulthood. In D. L. Tolman, \& L. M. Diamond (Eds.). APA handbook on sexuality and psychology: Volume 1 person-based approaches (pp. 487-522). Washington, DC: APA.

Halpern-Meekin, S., Manning, W. D., Giordano, P. C., \& Longmore, M. A. (2013). Relationship churning in emerging adulthood: On/Off relationships and sex with an Ex. Journal of Adolescent Research, 28, 166-188. http://dx.doi.org/10.1177/ 0743558412464524

Herzog, T., \& Hill-Chapman, C. (2013). Relationship formation and early risk exposure: Diverging associations with romantic self-concept and attachment. Journal of Adult Development, 20, 1-15. http://dx.doi.org/10.1007/s10804-012-9151-5 
Holman, T. B., \& Busby, D. M. (2011). Family of origin, differentiation of self and partner, and adult romantic relationship quality. Journal of Couple \& Relationship Therapy, 10, 3-19. http://dx.doi.org/ 10.1080/15332691.2010.539171

Jensen, T. M., Willoughby, B. J., Holman, T. B., Busby, D. M., \& Shafer, K. (2015). Associations between family and interpersonal processes and emerging adult marital paradigms: Does Adult Attachment Mediate? Journal of Adult Development, 22, 50-62. http://dx.doi.org/10.1007/s10804-0149200-3

Jose, A., O'Leary, D., \& Moyer, A. (2010). Does premarital cohabitation predict subsequent marital stability and marital quality? A meta-analysis. Journal of Marriage and Family, 72, 105-116. http://dx.doi .org/10.1111/j.1741-3737.2009.00686.x

Kennedy, S., \& Bumpass, L. (2008). Cohabitation and children's living arrangements: New estimates from the United States. Demographic Research, 19, 1663-1692. http://dx.doi.org/10.4054/DemRes .2008 .19 .47

Kim Halford, W., Pepping, C. A., Hilpert, P., Bodenmann, G., Wilson, K. L., Busby, D., . . . Holman, T. (2015). Immediate effect of couple relationship education on low-satisfaction couples: A randomized clinical trial plus an uncontrolled trial replication. Behavior Therapy, 46, 409-421. http://dx .doi.org/10.1016/j.beth.2015.02.001

Kuperberg, A. (2014). Age at coresidence, premarital cohabitation, and marriage dissolution: 19852009. Journal of Marriage and Family, 76, 352369. http://dx.doi.org/10.1111/jomf.12092

Leck, K. (2006). Correlates of minimal dating. The Journal of Social Psychology, 146, 549-567. http://dx.doi.org/10.3200/SOCP.146.5.549-567

Ledermann, T., \& Kenny, D. A. (2012). The common fate model for dyadic data: Variations of a theoretically important but underutilized model. Journal of Family Psychology, 26, 140-148. http://dx .doi.org/10.1037/a0026624

Leonhardt, N. D., Willoughby, B. J., Busby, D. M., Yorgason, J. B., \& Holmes, E. K. (2018). The significance of the female orgasm: A nationally representative, dyadic study of newlyweds' orgasm experience. Journal of Sexual Medicine, 15, 1140-1148. [Advance online publication.] http:// dx.doi.org/10.1016/j.jsxm.2018.05.018

Liu, G., Hariri, S., Bradley, H., Gottlieb, S. L., Leichliter, J. S., \& Markowitz, L. E. (2015). Trends and patterns of sexual behaviors among adolescents and adults aged 14 to 59 years, United States. Sexually Transmitted Diseases, 42, 20-26. http://dx.doi .org/10.1097/OLQ.0000000000000231

Manning, W. D., \& Cohen, J. A. (2012). Premarital cohabitation and marital dissolution: An examination of recent marriages. Journal of Marriage and
Family, 74, 377-387. http://dx.doi.org/10.1111/j $.1741-3737.2012 .00960 . x$

Meier, A., \& Allen, G. (2009). Romantic relationships from adolescence to young adulthood: Evidence from the National Longitudinal Study of Adolescent Health. The Sociological Quarterly, 50, 308-335. http://dx.doi.org/10.1111/j.15338525.2009.01142.x

Rauer, A. J., Pettit, G. S., Lansford, J. E., Bates, J. E., \& Dodge, K. A. (2013). Romantic relationship patterns in young adulthood and their developmental antecedents. Developmental Psychology, 49, 2159-2171. http://dx.doi.org/10.1037/a0031845

Rust, J., \& Golombok, S. (1986). The GRISS: A psychometric instrument for the assessment of sexual dysfunction. Archives of Sexual Behavior, 15, 157-165. http://dx.doi.org/10.1007/BF01542223

Saribay, S., \& Andersen, S. M. (2007). Are past relationships at the heart of attachment dynamics? What love has to do with it. Psychological Inquiry, 18, 183-191. http://dx.doi.org/10.1080/ 10478400701512786

Sassler, S., Addo, F. R., \& Lichter, D. T. (2012). The tempo of sexual activity and later relationship quality. Journal of Marriage and Family, 74, 708725. http://dx.doi.org/10.1111/j.1741-3737.2012 .00996.x

Seiffge-Krenke, I. (2003). Testing theories of romantic development from adolescence to young adulthood: Evidence of developmental sequence. International Journal of Behavioral Development, 27, 519-531. http://dx.doi.org/10.1080/01650250 344000145

Shulman, S., \& Connolly, J. (2013). The challenge of romantic relationships in emerging adulthood: Reconceptualization of the field. Emerging Adulthood, 1, 27-39. http://dx.doi.org/10.1177/ 2167696812467330

Siebenbruner, J. (2013). Are college students replacing dating and romantic relationships with hooking up? Journal of College Student Development, 54, 433-438. http://dx.doi.org/10.1353/csd.2013.0065

Simpson, J. (1987). The dissolution of romantic relationships: Factors involved in relationship stability and emotional distress [Electronic version]. Journal of Personality and Social Psychology, 53, 683-692. http://dx.doi.org/10.1037/0022-3514.53 .4 .683

Stanley, S. M., Amato, P. R., Johnson, C. A., \& Markman, H. J. (2006). Premarital education, marital quality, and marital stability: Findings from a large, random household survey. Journal of Family Psychology, 20, 117-126. http://dx.doi.org/10 .1037/0893-3200.20.1.117

Stanley, S. M., \& Markman, H. J. (1992). Assessing commitment in personal relationships. Journal of Marriage and the Family, 54, 595-608. http://dx .doi.org/10.2307/353245 
Stanley, S. M., Markman, H. J., \& Whitton, S. W. (2002). Communication, conflict, and commitment: Insights on the foundations of relationship success from a national survey. Family Process, 41, 659-675. http://dx.doi.org/10.1111/j.15455300.2002.00659.x

Stanley, S. M., Rhoades, G. K., Kelmer, G., Scott, S. B., Markman, H. J., \& Fincham, F. D. (2018). Unequally into "Us": Characteristics of individuals in asymmetrically committed relationships. Family Process. [Advance online publication.] http://dx .doi.org/10.1111/famp.12397

Stanley, S. M., Rhoades, G. K., \& Markman, H. J. (2006). Sliding vs. deciding: Inertia and the premarital cohabitation effect. Family Relations, 55, 499-509. http://dx.doi.org/10.1111/j.1741-3729 .2006.00418.x

Teachman, J. (2003). Premarital sex, premarital cohabitation, and the risk of subsequent marital dissolution among women. Journal of Marriage and Family, 65, 444-455. http://dx.doi.org/10.1111/j $.1741-3737.2003 .00444 . x$

Teachman, J. (2009). Premarital sex, premarital cohabitation, and the risk of subsequent marital dissolution among women. In N. B. Moore, J. J. Davidson, Sr., \& T. D. Fisher (Eds.), Speaking of sexuality: Interdisciplinary readings (pp. 195223). New York, NY: Oxford University Press.

Tolman, D. L., \& Diamond, L. M. (Eds.). (2013). APA handbook on sexuality and psychology: Volume 1. Person-based approaches. Washington, DC: APA.

Weissbourd, R., Anderson, T. R., Cashin, A., \& McIntyre, J. (2017). The talk: How adults can promote young people's healthy relationships and prevent misogyny and sexual harassment. Retrieved from https://mcc.gse.harvard.edu/files/gsemcc/files/mcc_the_talk_executive-summary.pdf

Willoughby, B. J., \& Carroll, J. S. (2016). On the horizon: Marriage timing, beliefs, and consequences in emerging adulthood. In J. J. Arnett (Ed.), The Oxford handbook of emerging adulthood (pp. 280-295). New York, NY: Oxford University Press.

Willoughby, B. J., Carroll, J. S., \& Busby, D. M. (2012). The different effects of "living together": Determining and comparing types of cohabiting couples. Journal of Social and Personal Relationships, 29, 397-419. http://dx.doi.org/10.1177/ 0265407511431184

Willoughby, B. J., \& James, S. L. (2017). The marriage paradox: Why emerging adults love marriage yet push it aside. New York, NY: Oxford University Press. http://dx.doi.org/10.1093/acprof: oso/9780190296650.001.0001

Woodger, M. J., Holman, T. B., \& Young, K. A. (2007). Latter-day Saint courtship patterns: Studies in religion and the social order. Ann Arbor, MI: University Press of America.

Yoshida, K., \& Busby, D. M. (2012). Intergenerational transmission effects on relationship satisfaction: A cross-cultural study. Journal of Family Issues, 33, 202-222. http://dx.doi.org/10.1177/ $0192513 X 11412883$

Received July 27, 2018

Revision received March 8, 2019

Accepted April 7, 2019

\section{E-Mail Notification of Your Latest Issue Online!}

Would you like to know when the next issue of your favorite APA journal will be available online? This service is now available to you. Sign up at https://my.apa.org/ portal/alerts/ and you will be notified by e-mail when issues of interest to you become available! 